\title{
Drugs Implicated, Mortality and Use of Corticosteroids in Toxic Epidermal Necrolysis Cases: A Systematic Review of Published Case Reports and Case Series
}

\author{
${ }^{1}$ Sharonjeet Kaur, ${ }^{2}$ Sujit Rajagopalan, ${ }^{3}$ Nusrat Shafiq, ${ }^{4}$ Sunil Dogra, ${ }^{5}$ Anand Srinivasan \\ ${ }^{6}$ Promila Pandhi, ${ }^{7}$ Samir Malhotra
}

\begin{abstract}
Background: Toxic epidermal necrolysis (TEN) is a rare idiosyncratic mucocutaneous reaction associated with high mortality. Drugs are most commonly implicated in TEN. The treatment constitutes stopping the offending drug, along with symptomatic management. In this study, we searched for case reports/series of TEN and analyzed data to find the most commonly implicated drugs in TEN, effects of use of corticosteroids on mortality in TEN patients, changing trends in mortality over the past 3 decades and difference in mortality rates in both developing and developed countries.
\end{abstract}

Materials and methods: We searched for case reports/series of TEN to evaluate most commonly implicated drugs in TEN, effects of use of corticosteroids on mortality in TEN patients, changing trends in mortality over the past three decades and difference in mortality rates in both developing and developed countries.

Results: Antibiotics (28.6\%) followed by antiepileptics (17.4\%) and nonsteroidal anti-inflammatory drugs (9.6\%) are most commonly implicated. There was nonsignificant decrease in mortality among steroids users as compared to nonusers $(\mathrm{OR}=2.0, \mathrm{Cl}$ 0.96-4.24). During the period between 1980 and 1989 the reported mortality in TEN cases was approximately $33.4 \%$, which decreased to $27 \%$ in the next two decades. There was a nonsignificant difference in mortality in developing countries as compared to developed countries (OR: 0.70, $\mathrm{Cl}$ 0.32-1.53).

Conclusion: Corticosteroids have been associated with non significant reduction in the mortality. Apart from this, mortality did not differ over years together in both developing and developed countries.

Keywords: Toxic epidermal necrolysis, Corticosteroids, Mortality.

How to cite this article: Kaur S, Rajagopalan S, Shafiq N, Dogra S, Srinivasan A, Pandhi P, Malhotra S. Drugs Implicated,

\footnotetext{
1,2,5Senior Resident, ${ }^{3}$ Assistant Professor, ${ }^{4}$ Associate Professor ${ }^{6}$ Ex-Head, ${ }^{7}$ Additional Professor

${ }^{1-3,5-7}$ Department of Pharmacology, Postgraduate Institute of Medical Education and Research, Chandigarh, India

${ }^{4}$ Department of Dermatology, Postgraduate Institute of Medical Education and Research, Chandigarh, India
}

Corresponding Author: Nusrat Shafiq, Assistant Professor Department of Pharmacology, Postgraduate Institute of Medical Education and Research, Chandigarh, India, e-mail: nusrat_shafiq@hotmail.com
Mortality and Use of Corticosteroids in Toxic Epidermal Necrolysis Cases: A Systematic Review of Published Case Reports and Case Series. J Postgrad Med Edu Res 2014;48(3):132-138.

\section{Source of support: Nil}

Conflict of interest: None

\section{INTRODUCTION}

Toxic epidermal necrolysis (TEN) is a rare life-threatening idiosyncratic mucocutaneous drug reaction characterized by widespread epidermal necrosis followed by epidermal detachment. ${ }^{1}$ Drugs, infections and immunizations are the most common causes of TEN. Drug-induced TEN is the commonest cause and antiepileptics, antibiotics, nonsteroidal anti-inflammatory drugs (NSAIDs), and allopurinol are the most commonly implicated agents. ${ }^{2}$

Prompt diagnosis and stoppage of suspected drugs is essential in the management of the TEN cases. This may be particularly challenging in some cases where multiple drugs are being used, especially when treatment discontinuation is not desirable. Although several review articles and textbooks have listed drugs causing TEN, they may not assist a clinician in deciding which drug, out of the several patients may be taking, has the highest probability of causing TEN.

Besides stopping the offending agent, treatment is mainly supportive, which includes, fluid replacement, correction of electrolyte imbalance, nutritional support, prevention of infection, and treatment with specific therapy. Cyclosporine, cyclophosphamide, plasmapheresis, intravenous immunoglobulin, and $\mathrm{N}$-acetylcysteine have been used for management and have shown inconsistent results. Corticosteroids are routinely used however, the evidence for their benefit is still lacking. ${ }^{3-10}$ The rationale behind conducting this study was to evaluate the changing trends in the TEN regarding drugs, mortality, and effectiveness of corticosteriods. The objective of this study was to identify drugs, more likely to cause TEN, the difference in mortality rates over the years and also between developed and developing nations and the effect of use of corticosteroids on mortality in TEN cases. The review was conducted by following the guidelines of preferred reporting items for systematic reviews and metaanalyses statement. 


\section{MATERIALS AND METHODS}

We searched the Medline, PubMed and Embase for published case reports and case series from 1950 to 2011. The MeSH TEN was used to elicit the articles. The subheading 'druginduced' was then added to short list only the relevant articles. Additionally, databases like Cochrane were also searched. References from identified articles were also scanned for additional relevant information. There was no publication limit in our literature search. Two independent authors evaluated the articles (SR, SK) and data was extracted and pooled and consensus was arrived. In case of discrepancy, it was resolved by third author (NS). All studies related to druginduced TEN were searched and further screened. Eligible studies were included in systematic review. The exclusion criteria for systematic review were animal studies, in vivo experiments, case reports of SJS or SJS-TEN overlap and insufficient information provided regarding determination of causative relation between drug and TEN.

Mean time for onset of symptoms, time to recovery or death was evaluated. Besides causality assessment, other parameters evaluated were commonly implicated diseases changing trends in the mortality over previous years as compared to recent years, and mortality rates in developing and developed countries and incidence of TEN among newer (approved after 1980) vs older drugs (approved till 1980). Data regarding different treatment modalities provided to patients during admission was also evaluated. Developing countries were defined on the basis of economy (gross domestic product, the per capita income, level of industrialization, amount of widespread infrastructure, and general standard of living) as a nation with a low living standard, undeveloped industrial base, and low human development index relative to other countries. Developed countries are the one with highly developed economy and advanced technological infrastructure relative to other less developed nations.

Causality assessment was done using a method of 'Karch and Lasagna' if the authors had not carried out the causality assessment themselves. ${ }^{11}$ The assessment in Karch and Lasagna method in relation to drugs implicated was based on temporal sequence, known response pattern to drug, improvement on dechallenge, reaction returns on rechallenge and alternative explanation. Further drugs implicated were classified either into definite, probable, possible and conditional.

Mortality was calculated based on the number of deaths from TEN as compared to number of cases that were analyzed in the review.

\section{STATISTICAL ANALYSIS}

Categorical data were expressed as $\mathrm{n}(\%)$ and quantitative data were expressed as mean \pm standard deviation. Compari- sons between groups were made using chi-square or Fisher's exact test. $\mathrm{p}<0.05$ was considered statistically significant. Odds ratio $(95 \% \mathrm{CI})$ was estimated to compare mortality between developing and developed countries. The primary analysis was done on published case reports/case series.

\section{RESULTS}

The 1214 hits were obtained when the search terms were combined. Out of these hits, we identified 161 cases which included both case reports and case series (Flow Chart 1).

The mean (standard deviation) time to onset of the prodromal symptoms, like fever and malaise, after the administration of the suspected drug was $12.3( \pm 17.4)$ days with median of 7 days ( 0.2 to 120 days). The mean age of presentation of TEN was 44 years with median of 45 years ( 0.2 to 93 years). Gender distribution was almost equal with a total of 83 males and 78 females presenting with TEN.

The most commonly implicated group of drugs were antibiotics, followed by antiepileptics, NSAIDs (Graph 1). Among the various antibiotics, beta-lactams, sulphonamides,

Flow Chart 1: Depicting the digible cases reports and series
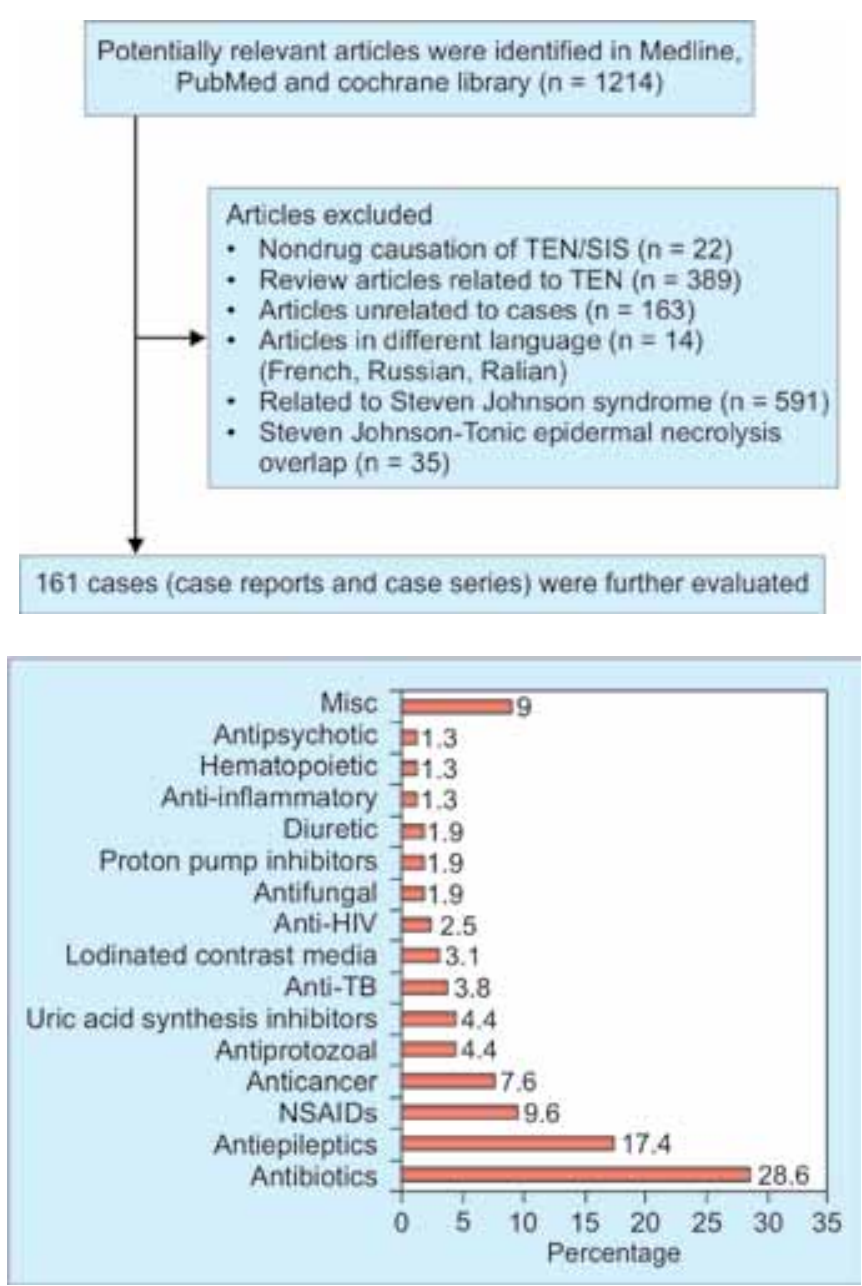

Graph 1: Commonly implicated drugs 
fluoroquinolones, and cephalosporins were commonly implicated drugs in antibiotic class (Graph 2).

Out of 161 cases of TEN, 139 were due to single drug and the rest were due to multiple drugs (Table 1). In one case, there was no data regarding drugs implicated and in another case, syndrome of inappropriate secretion of antidiuretic hormone (SIADH) was an alternate diagnosis. SIADH has been implicated as one of the causative factors of TEN. Broadly, the division is as shown in Table 1.

The primary diagnosis for which the suspected drugs were prescribed in majority was central nervous system diseases followed by disorders of respiratory system, musculoskeletal system, gastrointestinal system and infectious disease.

Causality assessment of drugs in cases of TEN revealed that in $9.3 \%$ of the cases causality was definite, in $63.3 \%$ of cases it was probable, in $20 \%$ of the cases it was possible and in $7.4 \%$ of the cases it was conditional (Graph 3).

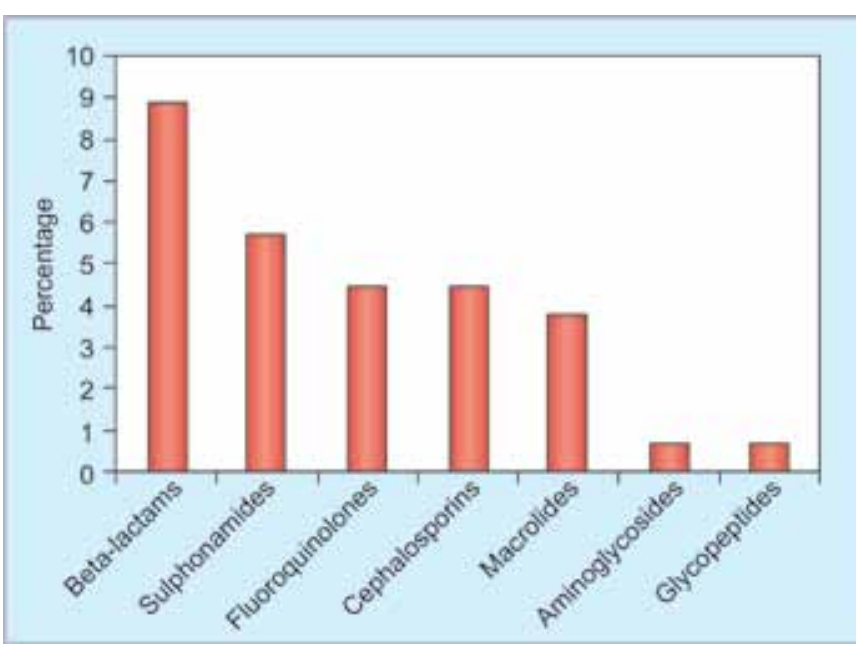

Graph 2: Commonly implicated class of antibiotics

Table 1: Drug combinations associated with TEN

\begin{tabular}{ll}
\hline Drug combinations/others & No. of cases \\
\hline Rifampicin + pyrizinamide + isoniazid & 3 \\
+ ethambutol & \\
Aspirin + cephalosporins + statins & 2 \\
Thalidomide + dexamethasone & 2 \\
Clarithromycin + disulfiram & 1 \\
Trimethoprim + amoxycillin & 1 \\
Sulfasalazine + tobramycin + ticarcillin & 1 \\
Allopurinol + iodinated contrast media & 1 \\
Nelfinavir/lamivudine plus zidovudine & 1 \\
Oxacillin + ampicillin + moxalactum & 1 \\
Amlobarbitone + trichloroethylene & 1 \\
Minoxidil + allopurinol & 1 \\
Pemetrexed and carboplatin with vitamin B12 & 1 \\
and folic acid & 1 \\
Phenobarbitone + phenolphthalein & 1 \\
Cetuximab plus minocycline & 1 \\
Indomethacin + acetylsalicylic acid & 1 \\
Carbamazepine + trimipramine & \\
\hline
\end{tabular}

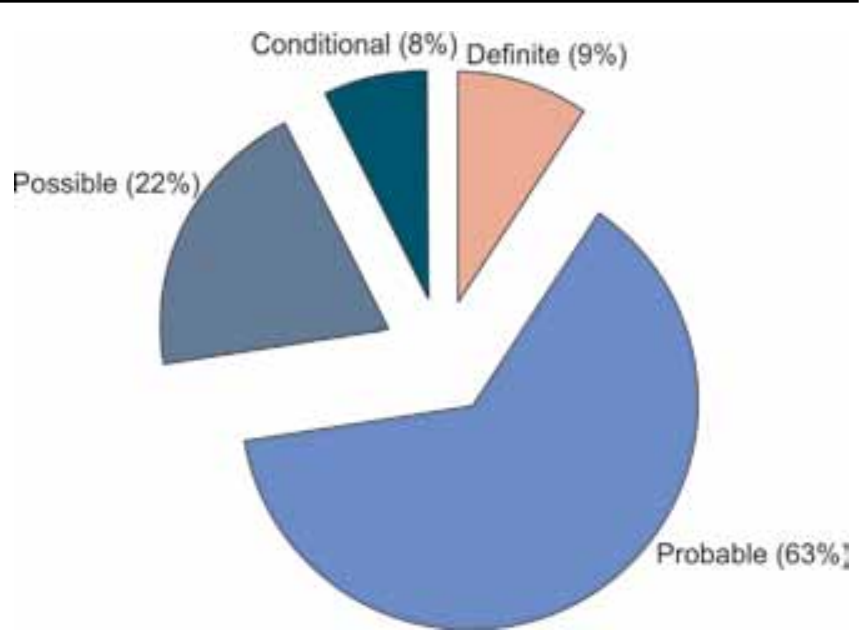

Graph 3: Causality assessment of drugs (\%)

Causality assessments of drugs implicated in TEN are shown in Table 2.

Corticosteroids were used in the management in 90 cases. Out of which, 71 (79\%) survived and $19(21.1 \%)$ died. Among total of 57 steroid nonusers, 37 (65\%) survived and $20(35.1 \%)$ died. This difference in mortality among steroid users and nonusers just missed statistical significance. $(\mathrm{OR}=2.0, \mathrm{CI}=0.96-4.24)$.

The mortality among TEN patients observed during the early decades (1980-1989) was approximately $33.4 \%$, which decreased to $27 \%$ (1990-1999). In 2000 to 2010 , the mortality remained $27.5 \%$ and in subsequent two years (2010-2011) it was 28\% ( $\mathrm{p}=0.96)(\mathrm{Graph} 4)$.

The overall mortality in the published studies was nonsignificant different in the developing countries as compared to developed countries (\%) (OR: 0.70, CI: 0.32-1.53).

The overall mean time to recover was $23.4 \pm 17.8$ days and death occurred within a mean time $15.8 \pm 18$ days. Rechallenge was carried out in 15 cases and in four cases mortality was observed.

\section{MANAGEMENT OF THE TEN CASES}

The first line in the management of TEN was to stop the offending drug. Supportive treatment in the form of intravenous fluids was given to all the patients. Antihistaminics were used in $14.2 \%$ and antimicrobial in $61.4 \%$ of the cases. Antifungals were prescribed in $6 \%$ patients to prevent complications related to TEN. Newer treatment modalities like intravenous immunoglobulins were administered in $18.6 \%$ of the cases, $5 \%$ received immunosuppressant and $2.4 \%$ received granulocyte macrophage colony stimulating factor (GMCSF). Appropriate care of cutaneous and ocular lesions was done if needed.

\section{DISCUSSION}

In this study, mean age at which TEN was observed was 44 years $($ Median $=45$ years) indicating that middle age 


\begin{tabular}{|c|c|c|c|c|c|}
\hline \multicolumn{3}{|c|}{ Table 2: Causality assessment of drugs } & \multirow{2}{*}{$\begin{array}{l}55 . \\
56 .\end{array}$} & \multirow{2}{*}{$\begin{array}{l}\text { Phenytoin } \\
\text { Mefloquine }\end{array}$} & \multirow{2}{*}{$\begin{array}{l}\text { Probable } \\
\text { Possible }\end{array}$} \\
\hline S.no. & Drugs & Causality & & & \\
\hline 1. & Aminosalicylic acid & Definite & 57. & Caspofungin & Probable \\
\hline 2. & Allupurinol & Probable & 58. & Capecitabine & Probable \\
\hline 3. & Benozaparen & Conditional & 59. & lohexol & Definite \\
\hline 4. & Mefloquine & Probable & 60. & Oflaxacin & Probable \\
\hline 5. & Cotrimoxazole & Probable & 61. & Norflox & Probable \\
\hline 6. & Moxifloxacin & Possible & 62. & Nevirapine & Probable \\
\hline 7. & Etritinate & Possibe & 63. & Nevirapine & Probable \\
\hline 8. & Amifostine & Conditional & 64. & Phenytoin & Probable \\
\hline 9. & Trimethoprim/sulphamethoxazole & Probable & 65. & Carbamazepine & Probable \\
\hline 10. & Ceftrixone & Conditional & 66. & Sulphasalzine/tobramycin/ticracillin & Probable \\
\hline 11. & Acetylsalicylic acid & Possible & 67. & Amoxycillin & Probable \\
\hline 12. & Herbal powder & Possible & 68. & Cotriamoxazole & Probable \\
\hline 13. & Chloroquinine & Possible & 69. & Allupurinol & Probable \\
\hline 14. & Chloroquinine & Possible & 70. & Darunavir/abacavir & Probable \\
\hline 15. & Chlorpromazine & Probable & 71. & lodinated contrast media & Definite \\
\hline 16. & Ciprofloxacin & Possible & 72. & Vancomycin/beta lactam & Probable \\
\hline 17. & Erythromycin & Probable & 73. & Paracetamol & Probable \\
\hline 18. & Tetramisole & Probable & 74. & Allopurinol & Probable \\
\hline 19. & Diluted diatrizoate & Conditional & 75. & Allopurinol & Probable \\
\hline 20. & Fluconazole & Probable & 76. & Allopurinol & Probable \\
\hline 21. & Indapamide & Probable & 77. & Allopurinol & Probable \\
\hline 22. & Tiecoplanin/amikacin & Conditional & 78. & Adefovir & Conditional \\
\hline 23. & Lamotrigene & Probable & 79. & Aspirin & Possible \\
\hline 24. & Nimesulide & Probable & 80. & Nelfinavir/lamivudine plus & Probable \\
\hline 25. & Omeprazole & Probable & & zidovudine & \\
\hline 26. & Carbamazepine & Probable & 81. & Phenobarbitone/whole brain & Probable \\
\hline 27. & Sulphasalzine & Possible & & radiotherapy & \\
\hline 28. & Methimazole & Probable & $\begin{array}{l}82 . \\
83\end{array}$ & Naproxen & Possible \\
\hline 29. & Mesalamine & Probable & 83. & Clarithromycin & Probable \\
\hline 30. & Clarithromycin & Probable & 84. & Etoricoxib & Probable \\
\hline 31. & Trimethoprim & Probable & 85. & Amoxycillin & Possible \\
\hline 32. & Trimethoprim/amoxycillin & Possible & 86. & Hydroxychloroquinine & Probable \\
\hline 33. & Methotrexate & Conditional & 87. & Isoniazid & Definite \\
\hline 34. & Voriconazole & Conditional & 88. & Lamotrigene & Probable \\
\hline 35. & Zonisamide & Probable & 89. & Phenytoin & Probable \\
\hline 36. & Lamotigene & Probable & 90. & Lamotrigene & Probable \\
\hline 37. & Carbamate poisoning & Conditional & 91. & Lansoprazole & Possible \\
\hline 38. & Ceftizimidine/vancomycin & Possible & 92. & Methotrexate & Possible \\
\hline 39. & Ceftizimidine/acyclovir & Possible & 93. & Ampicillin-sulbactum & Probable \\
\hline & Cefsulodin & & 94. & Cytosine arabinoside & Possible \\
\hline $\begin{array}{l}40 . \\
41\end{array}$ & Clindamycin & $\begin{array}{l}\text { Probable } \\
\text { Possible }\end{array}$ & 95. & Ferritin & Possible \\
\hline 41. & $\begin{array}{l}\text { Clindamycin } \\
\text { Clobazam }\end{array}$ & $\begin{array}{l}\text { Possible } \\
\text { Conditional }\end{array}$ & 96. & Phenytoin & Probable \\
\hline 42. & $\begin{array}{l}\text { Clobazam } \\
\text { Carbamazenine }\end{array}$ & & 97. & Phenytoin & Probable \\
\hline $\begin{array}{l}43 . \\
44\end{array}$ & Carbamazepine & $\begin{array}{l}\text { Probable } \\
\text { Conditional }\end{array}$ & 98. & Penicillin derivatives & Possible \\
\hline 44. & Famotidine & Conditional & 99. & Oral fluropyrimidine (5FU) & Possible \\
\hline $\begin{array}{l}45 . \\
46\end{array}$ & Lamotrigine & Probable & 100. & Tetrazepam & Possible \\
\hline 46. & $\begin{array}{l}\text { Methotrexate/trimethoprim } \\
\text { sulphamethoxazole }\end{array}$ & Probable & 101. & Ciprofloxacin & Probable \\
\hline 47. & Trimethoprim & Possible & 102. & Thiacetazone & Probable \\
\hline 48. & Thalidomide & Probable & 103. & Thiacetazone & Probable \\
\hline 49. & Sidenafil & Conditional & 104. & Amlobarbitone & Probable \\
\hline 50. & Sparfloxacin & Probable & 105. & Celecoxib & Possible \\
\hline 51. & Ceftrixone & Definite & 106. & Voriconazole & Probable \\
\hline 52. & Trimethoprim/sulphomethoxazole & Probable & 107. & Gabapentin & Possible \\
\hline 53. & Contrast media & Definite & 108. & Lamotrigene & Possible \\
\hline 54. & Phenytoin & Probable & 109. & Cetuximab & Possible \\
\hline
\end{tabular}




\begin{tabular}{|c|c|c|}
\hline 110. & Celecoxib & Possible \\
\hline 111. & Carbamazepine & Probable \\
\hline 112. & Paracetamol & Possible \\
\hline 113. & Baclofen & Probable \\
\hline 114. & Trazodone & Probable \\
\hline 115. & Captopril & Probable \\
\hline 116. & Minoxidil & Probable \\
\hline 117. & Allopurinol & Probable \\
\hline 118. & Procaine penicillin & Probable \\
\hline 119. & Amoxycillin/cefalexin & Probable \\
\hline 120. & Ampicillin-sulbactum & Probable \\
\hline 121. & $\begin{array}{l}\text { Cefuroxime, allopurinol and/or } \\
\text { amoxicillin/clavulanic acid }\end{array}$ & Probable \\
\hline 122. & Augmentin & Probable \\
\hline 123. & $\begin{array}{l}\text { Pemetrexed and carboplatin with } \\
\text { Vit B12 and folic acid }\end{array}$ & Possible \\
\hline 124. & Hypericum & Probable \\
\hline 125. & Phenolphthalein and aloin & Definite \\
\hline 126. & Blood purifying pills & Probable \\
\hline 127. & Penicillic derivatives & Definite \\
\hline 128. & $\begin{array}{l}\text { Imipenam/cilastatin/ } \\
\text { meropenam }\end{array}$ & Definite \\
\hline 129. & Pentobarbitonum sodium & Probable \\
\hline 130. & Leflunomide & Probable \\
\hline 131. & Lamotrigene & Probable \\
\hline 132. & Lenalidomide & Probable \\
\hline 133. & Pseudoephidrine & Definite \\
\hline 134. & Thalidomide & Probable \\
\hline 135. & Clarithromycin & Definite \\
\hline 136. & Telithromycin & Definite \\
\hline 137. & Ampicillin & Definite \\
\hline 138. & Omeprazole & Probable \\
\hline 139. & Carvidilol & Probable \\
\hline 140. & Indomethacin & Probable \\
\hline 141. & Phenylbutazone & Probable \\
\hline 142. & Paroxitine & Probable \\
\hline 143. & Aerosolized pentamidine & Definite \\
\hline 144. & $\begin{array}{l}\text { Rifampicin, isoniazid, pyrazinamide } \\
\text { and ethambutol }\end{array}$ & Probable \\
\hline 145. & $\begin{array}{l}\text { Rifampicin, isoniazid, pyrazinamide } \\
\text { and ethambutol }\end{array}$ & Probable \\
\hline 146. & $\begin{array}{l}\text { Rifampicin, isoniazid, pyrazinamide } \\
\text { and ethambutol }\end{array}$ & Probable \\
\hline 147. & Aspirin/cefuroxime/pravastatin & Probable \\
\hline 148. & Trimethoprim-sulphamethoxazole & Probable \\
\hline 149. & Brinzolamide & Probable \\
\hline 150. & Dorzolamide & Probable \\
\hline 151. & Cetuximab plus minocycline & Definite \\
\hline 152. & Oxaprozin & Probable \\
\hline 153. & Cetuximab & Probable \\
\hline 154. & Lamotrigene & Probable \\
\hline 155. & Trovafloxacin & Probable \\
\hline 156. & Docetaxel & Probable \\
\hline 157. & Lmitinib & Probable \\
\hline 158. & Indomethacin & Possible \\
\hline 159. & Lamotrigene & Probable \\
\hline 160. & Carbamazepine & Probable \\
\hline 161. & Carbamazepine & Probable \\
\hline
\end{tabular}

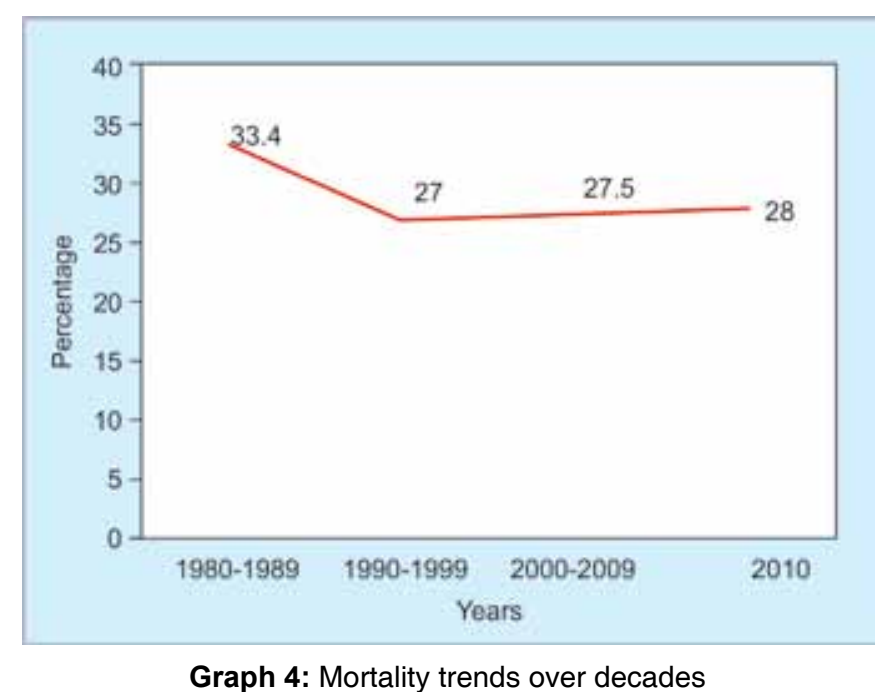

group people are more susceptible to TEN. No significant difference in terms of gender was seen among the reported TEN cases. This systematic review of published case reports/ series of TEN found that antibiotics followed by the antiepileptics and NSAIDs were the most frequently implicated drugs necessitating vigilance on the part of prescribers regarding these drugs. This data is very much similar to the previous studies regarding drugs implicated in TEN. ${ }^{1,12-15}$ In this study, among the antibiotics, beta-lactams were the foremost causative agent followed by sulphonamides and fluroquinolones. Previous studies have shown sulphonamides to be the foremost causative agents among antibiotics. Beta-lactams were found to be most common group of drugs causing TEN. This may be because of discovery of newer congeners like cephalosporins. Another reason could be that beta-lactams have been widely prescribed. In comparison to our study, EuroSCAR study reported strong association of TEN with nevirapine and lamotrigine among newer drugs and among older drugs sulphonamides followed by allopurinol, carbamazepine, phenobarbitone, phenytoin and oxicams. ${ }^{16}$

Single drugs were suspected in causing TEN as compared to multiple drugs. A physician should have adequate awareness regarding drugs indicated in TEN.

Our study found that in $63.3 \%$ of the reported cases, drugs implicated had a probable causation. A definite causality requires a rechallenge test to be performed. Since majority of the TEN cases are severe, it becomes difficult to perform rechallenge in most of the cases. Hence, a definite causality is difficult to arrive at.

Since TEN is an immunologically mediated reaction, it is but rational to use corticosteroids to suppress it. However, use of corticosteroids may increase the risk of infection, delay healing of lesions, mask early signs of sepsis and induce severe gastrointestinal bleeding. Hence, the use of corticosteroids in TEN cases is debatable. Previous studies reveal conflicting results regarding corticosteroid use in 
the management of TEN cases. Some studies have reported corticosteroids as life saving if given early and especially in high doses (pulse therapy) for few days. ${ }^{17-19}$ Other studies have reported that corticosteroid treatment does not affect the mortality in TEN. ${ }^{20-22}$ Again, some other studies have reported an increase in mortality and morbidity in TEN cases treated with corticosteroids. ${ }^{23,24}$ Infact, one study reports corticosteroids as being causative of TEN ${ }^{25}$ In our systematic review, treatment with steroid was found to be associated with a nonsignificant decrease in the mortality in the TEN cases. Since, this data is derived from case reports/ series, a definite conclusion cannot be derived on the basis of this study. We require further well conducted, randomized clinical trials to determine the place of steroid therapy in the management of TEN cases.

Mortality in TEN cases during the period between 1980 and 1989 was $33.4 \%$. This decreased to $27 \%$ in the next two decades although this decrease was not significant. This underlines a need for better diagnostic and treatment modalities for this condition and also more vigilance on the part of the prescribing physicians.

The difference in mortality indices in both developed and developing countries were nonsignificant, pointing toward good patient care in the developing nations which is at par with developed countries. On the contrary this might also be due to reporting bias in the developing nations due to a lack of good healthcare infrastructure. The main limitation of the study is that of publication bias from analysis of case reports and case series from Medline, PubMed, Cochrane and Embase leading to publication bias.

In less than $20 \%$ of the patients GMCSF, immunoglobulins and immunosuppressants were prescribed. These drugs are not approved for treating TEN and their efficacy in treating such cases need to be established by conducting randomized clinical trials. If proven efficacious they will add to the resources available to treat TEN successfully.

\section{CONCLUSION}

The best way to manage TEN is to detect it by constant vigilance, early diagnosis and prompt institution of therapy. Initial therapy should include maintenance of hydration, controlling pain, preventing secondary infection, and long term sequel. No specific treatment has shown to be effective. Role of corticosteroids in management of TEN has to be explored by conducting proper randomized controlled trials.

Questions which need to be addressed regarding the treatment of TEN:

1. How can we generate good quality evidence investigating the role of corticosteroids in TEN?

2. How can better understanding of pathophysiology of TEN lead to change in mortality?
3. What steps should be followed to prevent drug induced TEN?

4. What would be the effect of time to initiation of therapy on mortality in TEN?

5. What steps should be taken to stop to prevent long-term complication?

6. How can we bridge the gap between onset of TEN (prodromal symptoms) and full blown TEN?

7. What could be the reasons for differences in mortality trends in developing and developed countries though nonsignificant?

8. What steps should be taken to decrease the trend of mortality in both developing and developed countries?

\section{REFERENCES}

1. Roujeau JC, Stern RS, Wintroub BU. Cutaneous drug reactions. In: Kasper DL, Braunwald E, Fauci AS, Hauser SL, Longo DL, Jameson JL, editors. Harrison's Principles of Internal Medicine. 17th ed. New York: McGraw-Hill. 2008.p.343-350.

2. Roujeau JC, Kelly JP, Naldi L, Rzany B, Stern RS, Anderson T, Auquier A, Bastuji-Garin S, Correia O, Locati F, et al. Medication use and the risk of Stevens-Johnson syndrome or toxic epidermal necrolysis. N Engl J Med 1995;333(24):1600-1607.

3. French LE. Toxic epidermal necrolysis and Stevens Johnson syndrome: our current understanding. Allergol Int 2006;55(1): 9-16.

4. Heng MC, Allen SG. Efficacy of cyclophosphamide in toxic epidermal necrolysis. Clinical and pathophysiologic aspects. J Am Acad Dermatol 1991;25(5):778-786.

5. Kamanabroo D, Schmitz-Landgraf W, Czarnetzki BM. Plasmapheresis in severe drug-induced toxic epidermal necrolysis. Arch Dermatol 1985;121(12):1548-1549.

6. Valeyrie-Allanore L, Wolkstein P, Brochard L, Ortonne N, Maitre B, Revuz J, Bagot M, Roujeau JC. Open trial of ciclosporine treatment for Stevens Johnson syndrome and toxic epidermal necrolysis. Br J Dermatol 2010;163(4):847-853.

7. Redondo P, De Felipe I, De la Pena A, Aramendia JM, Vanaclocha V. Drug-induced hypersensitivity syndrome and toxic epidermal necrolysis. Treatment with $\mathrm{N}$-acetylcysteine. Br J Dermatol 1997;136(4):645-646.

8. Prins C, Kerdel FA, Padilla RS, Hunziker T, Chimenti S, Viard I, Mauri DN, Flynn K, Trent J, Margolis DJ, et al. Treatment of toxic epidermal necrolysis with high-dose intravenous immunoglobulins: multicenter retrospective analysis of 48 consecutive cases. Arch Dermatol 2003;139(1):26-32.

9. Halebian PH, Corder VJ, Madden MR, Finklestein JL, Shires GT. Improved burn center survival of patients with toxic epidermal necrolysis managed without corticosteroids. Ann Surg 1986; 204(5):503-512.

10. Bastuji-Garin S, Fouchard N, Bertocchi M, Roujeau JC, Revuz J, Wolkenstein P. SCORTEN: a severity-of-illness score for toxic epidermal necrolysis. J Invest Dermatol 2000;115(2):149-153.

11. Karch FE, Lasagna L. Toward the operational identification of adverse drug reactions. Clin Pharmacol Ther 1977;21(3):247-254.

12. Kaufman DW. Epidemiologic approaches to the study of toxic epidermal necrolysis. J Invest Dermatol 1994;102(6):31S-33S.

13. Schopf E, Stuhmer A, Rzany B, Victor N, Zentgraf R, Kapp JF. Toxic epidermal necrolysis and Stevens-Johnson syndrome. 
An epidemiologic study from West Germany. Arch Dermatol 1991:127(6):839-842.

14. Shear NH, Spielberg SP, Grant DM, Tang BK, Kalow W. Differences in metabolism of sulfonamides predisposing to idiosyncratic toxicity. Ann Intern Med 1986;105(2):179-184.

15. Wolkenstein P, Charue D, Laurent P, Revuz J, Roujeau JC, Bagot M. Metabolic predisposition to cutaneous adverse drug reactions. Role in toxic epidermal necrolysis caused by sulfonamides and anticonvulsants. Arch Dermatol 1995;131(5):544-551.

16. Mockenhaupt M, Viboud C, Dunant A, Naldi L, Halevy S, Bouwes Bavinck JN, Sidoroff A, Schneck J, Roujeau JC, Flahault A. Stevens-Johnson syndrome and toxic epidermal necrolysis: assessment of medication risks with emphasis on recently marketed drugs. The EuroSCAR-Study. J Invest Dermatol 2008;128(1):35-44.

17. Stables GI, Lever RS. Toxic epidermal necrolysis and systemic corticosteroids. Br J Dermatol 1993;128(3):357.

18. Van der Meer JB, Schuttelaar ML, Toth GG, Kardaun SH, Beerthuizen G, de Jong MC, Jonkman MF, Nieuwenhuis P. Successful dexamethasone pulse therapy in a toxic epidermal necrolysis (TEN) patient featuring recurrent TEN to oxazepam. Clin Exp Dermatol 2001;26(8):654-656.

19. Khoo AK, Foo CL. Toxic epidermal necrolysis in a burns centre: a 6-year review. Burns 1996;22(4):275-278.

20. Ducic I, Shalom A, Rising W, Nagamoto K, Munster AM. Outcome of patients with toxic epidermal necrolysis syndrome revisited. Plast Reconstr Surg 2002;110(3):768-773.

21. Rasmussen JE. Toxic epidermal necrolysis. A review of 75 cases in children. Arch Dermatol 1975;111(9):1135-1139.

22. Schulz JT, Sheridan RL, Ryan CM, MacKool B, Tompkins RG. A 10-year experience with toxic epidermal necrolysis. J Burn Care Rehabil 2000;21:199-204.

23. Murphy JT, Purdue GF, Hunt JL. Toxic epidermal necrolysis. J Burn Care Rehabil 1997;18(5):417-420.

24. Kelemen JJ, Cioffi WG, McManus WF, Mason AD Jr, Pruitt BA Jr. Burn center care for patients with toxic epidermal necrolysis. J Am Coll Surg 1995;180(3):273-278.

25. Rzany B, Schmitt H, Schopf E. Toxic epidermal necrolysis in patients receiving glucocorticosteroids. Acta Derm Venereol 1991;71(2):171-172. 